\title{
Back-Shoring vs. Near-Shoring: A Comparative Study
}

\author{
Fernando MERINO ${ }^{\mathrm{a}}$, Cristina DI STEFANO ${ }^{\mathrm{b}}$ and Luciano FRATOCCHI ${ }^{\mathrm{b}, 1}$ \\ ${ }^{a}$ Department of Applied Economy, University of Murcia, Spain \\ ${ }^{\mathrm{b}}$ Department of Industrial and Information Engineering and Economics, \\ University of L'Aquila, Italy
}

\begin{abstract}
After decades of manufacturing offshoring strategies, generally addressed to low cost countries, in the last few years companies have been increasingly revising their location strategies. In so doing, they often implement either backshoring (relocation to the home country) or near-shoring (relocation to the home region) alternatives. While the former strategy has gained increasing attention among scholars in recent years, studies on near-shoring are still scarce. Moreover, the academic literature rarely compares the two phenomena in order to understand why companies prefer to implement one instead of the other. This paper aims to shed new light on similarities and differences among back- and near-shoring strategies. In order to reach such an objective, we assume a contingency approach by focusing on a specific industry, the footwear sector, which has been significantly characterized by offshoring strategies. In order to reach the research aim, the comparison between back- and near-shoring strategies will be conducted focusing on three main issues: a) characteristics of the companies implementing the relocation strategy (firm's size); b) motivations inducing companies to relocate; c) barriers to the implementation of the relocation decision. Given the explorative nature of the paper, the features of 41 back- and near-shoring decisions implemented by 25 Italian and Spanish companies operating in the footwear industry will be analysed. Preliminary findings show smaller companies are more likely to backshore instead of near-shore, probably because of the lower competences and resources they own. At the same time, availability of skilled contractors and/or availability of government aid in the home country induce them to back-shore instead of near-shore. Finally, the lack of skilled suppliers mainly characterizes the back-shoring alternative.
\end{abstract}

Keywords. Reshoring, Back-shoring, Near-shoring, Footwear

\section{Introduction}

Western manufacturing companies have been implementing offshoring strategies - often coupled with out-sourcing ones - since the '80s. Such a location decision has often been considered as the only strategic alternative to remain competitive in the global market, due to the increasing competitiveness of emergent and less developed countries (e.g. Asia, Latin America) [1]. However, several disturbances affected firms' supply chains and companies then had to develop strategies to cope with them [2]. Therefore, at least in the last decade, several manufacturing companies have been increasingly reviewing their earlier location strategies, often redesigning their production footprint at the worldwide

\footnotetext{
${ }^{1}$ Corresponding author. luciano.fratocchi@univaq.it
} 
level [3]. More specifically, they implemented one or more of the so-called "relocation of second degree" [4] or "reshoring" strategies [5] [6]. This means they decided to relocate production activities according to one of the following three alternatives: a) back-reshoring [5] or "Relocation at the home country" [4]; b) near-reshoring (relocation to the company's home region); c) further offshoring (relocation to a region far away from the home one). [4] jointly define near-reshoring and further offshoring as "Relocation to a third country", independently of the geographic distance with respect to the home country.

While the further offshoring alternative is consistent with the traditional linear conceptualization of the internationalization process [7] [8], the other two options are based on the concept of "nonlinear internationalization," i.e. an internationalization path "characterized by substantial increases and decreases in international activity" [9]. Therefore, they deserve specific attention by scholars [10] [11]. However, the terms back-reshoring and near-reshoring suggested by [10] are not particularly diffused in the extant reshoring literature. Therefore, in this paper we prefer to refer to the more adopted terms of near-shoring and back-shoring adopted by [6].

While the back-shoring phenomenon has gained increasing attention among scholars in recent years [12] [13] [14], studies on near-shoring are still scarce [15]. More specifically, the academic literature rarely compares the two phenomena in order to understand why companies prefer to implement one instead of the other [16]. At the same time, [17] explicitly requested future research should define criteria to compare near- and back-shoring alternatives. This request assumes a growing relevance when you consider [18] pointed out that near-shoring "is still a limited phenomenon [...] but it is reasonable to assume $[\ldots$ it ...] will relatively soon increase significantly". Authors justify their statement by pointing out that the near-shoring alternative combines the advantages of both offshoring and back-shoring strategies [18].

Based on this theoretical background, this paper aims to shed new light on similarities and differences among back- and near-shoring strategies. In order to reach such an objective, we assume a contingency approach by focusing on a specific industry as suggested by [19]. More specifically, analysis will be centred on the footwear industry which has been significantly characterized by offshoring strategies in the last few decades [20]. In this respect, during the 2010 s, over $90 \%$ of apparel and footwear companies in the US moved their production activities overseas [17]. However, within the same industry, some evidence of back-shoring strategies has emerged. For instance, [21] showed that 10 out of the 15 major Spanish companies located in the Alicante industrial district in the previous five years decided to back-shore, independently of their product lines (e.g. dress shoes vs. sport ones) and market targets (mid-range vs. mid-high and high ones). At the same time, similar evidence has also been pointed out in Italy [22] [16] and Portugal [23]. However, to the best of our knowledge, there is no research comparing back-shoring and near-shoring strategies in this (or any other) industry.

In order to reach the research aim, a comparison between back- and near-shoring strategies will be conducted, focusing on three main issues: a) characteristics of the companies implementing the relocation of second degree (firm's size); b) motivations inducing companies to relocate; c) barriers to the implementation of the relocation decision. Given the explorative nature of the paper, the features of 41 back- and nearshoring decisions implemented by 25 Italian and Spanish companies operating in the footwear industry will be analysed. The analysis, as it combines the situation of two countries, eliminates any bias due to an idiosyncratic situation of one of them, thus providing more robust results. 
The rest of the paper is structured as follows: the next section will contain a structured literature review of both the back- and near-shoring phenomena. More specifically, 124 Scopus indexed journal articles published up to 31 July 2019 will be analysed, in order to present the state-of-the-art in this question. Section 2 will contain a description of the sampled back- and near-shoring decisions while in section 3 quantitative findings will be presented. Main conclusions and implications for scholars, managers and policy makers will be summarized in the last section.

\section{Theoretical background and research questions}

\subsection{The extant literature on back-shoring and near-shoring decisions}

In order to define the theoretical background of the back-shoring and near-shoring phenomena, attention has been focused on Scopus indexed journal articles published in the English language until June 2019. More specifically, for analysing the back-shoring phenomenon we checked the title, abstract and keywords for the following terms: a) "reshor*"; b) "re-shor*"; c) "backshor*"; d) "back-shor*"; e) "back-reshor*"; f) "backsourc*". We found a total number of 177 journal articles; after all the co-authors had carefully read the full text of these articles, the following excluding criteria were adopted:

- journal articles focusing on back-shoring of firms operating in industries different from manufacturing ones (e.g. ICT companies);

- documents published in sources without peer review systems;

- journal articles in which the searched terms are used to indicate a different concept from the one of interest (for instance, some of the keywords belonging to the reshoring concept are used with different meanings in the maritime and building engineering research fields);

- documents referring to functions other than operations (e.g. human resources and research and development (R\&D)).

Based on these criteria, 62 documents were eliminated; therefore, the total amount of sampled documents was 115 .

At the same time, to describe the state-of-the-art of near-shoring literature, we replicated the same research methodology checking the title, abstract and keywords for the following terms: a) "near/shor*"; b) "nearshor*" c) "near-reshor*".

We collected 102 documents in total. Exclusion criteria were defined considering that the term near-shoring has been adopted with different meanings in the literature of different subject areas. For instance, it is used in the engineering and environmental science fields of study to refer to the littoral zone that is "the part of a sea, lake, or river that is close to the shore" (https://en.wikipedia.org/wiki/Littoral_zone). In the international business and supply chain management research areas, the term has been adopted with a further two meanings: a) a specific type of offshoring strategy addressed to a host country located in the home region [24] [25] [26] [27] [15]; b) a "relocation of second degree" [4] in a host country located in the home region. In this respect, it is worth noting that at least one journal article simultaneously adopts the term near-shoring to refer to both concepts [2]. In this paper we assume as a reference the second concept of near-shoring strategies, since we are interested in analysing post-offshoring firms' decisions [28]. Therefore, we excluded:

- documents regarding environment-related conceptualizations of the near-shoring term (69); and 
- articles focusing on relocation of service companies (five documents) and/or firm's functions being different from the production one (2).

The full texts of the remaining 26 articles were analysed by all co-authors; based on that analysis, 17 documents regarding the offshoring decision addressing countries in the same home region were eliminated. A final number of nine articles were then considered as relevant for defining the theoretical background of the paper.

\subsection{Findings of the literature review}

Selected articles on back-shoring have been published since 2007while those regarding near-shoring only since 2012. Documents were published mainly in operation and supply chain management journals, as in the case of the wider reshoring extant literature [4]. Within the sampled literature, only two articles compare the near-shoring alternative with the other two relocations of second degree [4], namely back-shoring and further offshoring [5]. More specifically, while [29] consider back- and near-shoring as "similar strategies", [30] found near-shoring should be preferred to the further offshoring alternative when the company aims to improve its market responsiveness; otherwise the relocation to an far away host country should be preferred when the company goal is cost efficiency.

Regarding the first issue of interest of this paper - the impact (if any) of size on back- and near-shoring decisions - the sampled literature regarding the relocation to the home country clearly shows that firm's size is recognized as a contingency factor to be taken into account when analysing the relocation to the home country [19][31]. This induced [32] and [33] to develop back-shoring decision making models specifically tailored for Small and Medium Enterprises (SMEs). When considering the diffusion of back-shoring decisions according to firm's size, differences among scholars emerge. More specifically, articles based on German data [34] [35] [36] show large companies are more likely to implement the relocation strategy under investigation. However, it must be taken into account that such scholars conceptualize the back-shoring decision as a correction of a previous mistake; in other words, the company discovered the decision to produce abroad implied several unforeseen negative consequences, such as higher coordination costs. In other words, if the company management had perceived such problems in advance, it would not have implemented the initial offshoring decision. This conceptualization of the back-shoring decision is not the only one proposed in the extant literature. For instance, [22] found Spanish footwear companies relocated manufacturing activities to the home country when there were changes in the relevant competitive environment. Similarly [16] and [23] showed back-shoring decisions may be the result of a firm's "strategic shift". The higher propensity of large firms to back-shore, when compared to SMEs, has also been found in Scandinavian ones [37] [38] [39]. However, [40] showed New Zealand SMEs have a higher propensity to back-shore when compared to larger ones. Finally, other scholars [41] [11] [13] found that back-shoring is almost equally distributed among the two classes of firm's size. Of specific note is the [31] finding regarding the offshoring duration, i.e. the time that elapsed between the decision to offshore and the one to back-shore. In this respect, the authors found SMEs generally relocate production to the home country after a shorter time; this could - at least partially - be explained by the lower amount of resources such companies own. In other words, given the resources' scarcity when encountering problems abroad, SMEs are more likely to back-shore than to remain offshore and try to cope with the foreign environment. In 
the near-shoring literature, the only journal article investigating this issue [41] did not find any difference between companies back-shoring and those near-shoring.

Regarding the second issue investigated in this study - the impact (if any) of motivations in choosing between back- and near-shoring alternatives - it must be noted that the motivation issue is the most investigated in the extant back-shoring literature. Scholars' proposition that dozens of variables influence the phenomenon clearly emerges [4]; they are not only related to cost issues (e.g. logistics costs and reduction of the labour cost gap between host and home country) but also to the firm's effectiveness (e.g. the "made in effect" and higher responsiveness to customer needs). Based on such evidence, some authors' proposed frameworks aimed to classify such large amount of motivations; among them, [11] developed a theoretically-based model which takes into account the motivation origin (dividing between those belonging to the company and those belonging to the external environment) and nature (drivers oriented to cost efficiency vs. those regarding value effectiveness). Also, for near-shoring, scholars proposed several drivers, ranging from cost-related ones (e.g. labour and coordination costs) to value-related ones (e.g. poor product quality and lead time). Moreover, [42] referred to intellectual property and regulatory issues. Therefore, scholars seem to maintain that motivations for relocating production activities to the home region are no different from the ones characterizing the back-shoring phenomenon.

When considering the third issue investigated in this paper - the impact (if any) of barriers to the back- and near-shoring decisions - it must be noted that the issue regarding variables that may impede the implementation of decisions to relocate production activities has been investigated only in the last three years. For instance, [43] proposed as a main barrier the limited availability of suppliers in the home country, since the deindustrialization effects of earlier waves of offshoring strategies. More recently, [34] added further elements, such as the amount of internal resources owned by the backshoring companies and their relationships with the industrial network. At the same time, [44] [45] specifically referred to the relevance of a firm's readiness, in terms of competences required, to back-shore production. Finally, [46] [47] developed a list of 24 barriers ranging from home country labour market features to internal competency. In contrast, no articles were found that addressed the issue related to barriers that may impede the implementation of near-shoring decisions.

\subsection{Research questions}

The earlier conducted literature reviews, regarding the back- and near-shoring decisions, confirm that analyses comparing these two phenomena are quite scant. However, findings that emerged earlier may be adopted to develop research hypotheses regarding the three chosen issues, namely firm's size, relocation motivations and barriers to implementation.

Regarding the impact of firm's size, the discussion on the back-shoring sampled literature provides evidence that larger companies generally have higher financial and human resources which allow them to have a wider manufacturing footprint at the worldwide level [48] [49] [50] and to remain abroad for a longer time (offshoring duration, [31]). In this respect, it must be taken into account that while back-shoring strategies eliminate coordination costs inherent to offshore production, near-shoring ones still imply them. Based on such evidence, it may be speculated that firm's size will also 
impact on the preference to maintain production activities abroad instead of back-shoring them. Therefore, we speculate as follows

HP 1. The smaller the company, the higher the propensity to back-shore instead of near-shore.

As noted earlier, the only commonality between the two investigated streams of literature is regarding motivations, which may induce companies to implement a relocation of second degree. However, further speculations may be developed on this issue. More specifically, while cost-related issues seem not to be relevant in discriminating between relocation to the home country (back-shoring) instead of to the home region (near-shoring), the former alternative should be preferred when the home country offers higher comparative advantages with respect to one in the home region. In this respect, three main issues seem to be relevant: impact of the "made in effect" (i.e., the higher value products gain when produced in the home country instead of abroad although in a nearby country) on customers' willingness to buy [51], availability of skilled contractors and government aid. Therefore, we speculate as follows:

HP 2a. The higher the relevance perceived by the reshoring company in terms of the "made in effect", the higher the propensity to back-shore;

$H P 2 b$. The higher the relevance perceived by the reshoring company in terms of "availability of skilled contractors", the higher the propensity to back-shore;

$H P 2 c$. The higher the relevance perceived by the reshoring company in terms of "availability of government aid", the higher the propensity to back-shore.

Consequently, we may assume that back-shoring strategies are mainly impeded by difficulties in reorganizing manufacturing activities in the home country, either in the case of out-sourcing governance mode (availability of skilled contractors) or in that of re-internalization (creation of internal manufacturing competences). Therefore, we speculate as follows:

HP $3 a$. The higher the propensity to back-shore, the higher the impact of barriers related to the availability of skilled contractors;

$H P 3 b$. The higher the propensity to back-shore, the higher the impact of barriers related to the development of internal manufacturing competences.

\section{Sample description and research methodology}

In order to reach the research aims presented earlier, data regarding Spanish and Italian companies have been collected through a common questionnaire delivered in both countries. The two countries have been selected since in both of them, the footwear industry has a long tradition that can be traced back to the second half of the 19th century. Moreover, they represent two of the most important production locations within the European Union (28 countries) since Spain and Italy account respectively for $13 \%$ and $48 \%$ of the total value of the continental footwear industry in 2017 . However, while Italian companies generally produce medium/high- and high-end products, Spanish companies are more focused on medium-end products. As a matter of fact, while the average price for Italian output is $54.9 € /$ pair, the Spanish output is $24.6 € /$ pair. Finally, Italy and Spain share some features in their internationalization processes [52] as well as some differences, given their existing international networks. More specifically, while Italian companies are more focused on the Balkans and some East European countries, Spanish ones are located in North Africa or Latin American countries. 
The adopted questionnaire was articulated in three main parts, the first of which collects information on the surveyed firms in terms of size (e.g., firm' sales, number of employees), international propensity (valuated in terms of percentage of exports on total sales), target markets (economic, medium, medium-fine, fine and luxury) and sources for competitive advantage (quality service and delivery time, design, advertising, brand, production costs). The second section addressed the initial offshoring strategy; therefore, questions were regarding the "what" of the first relocation decision (e.g. product line(s) and/or production phase(s)), the "why" (e.g. motivations/drivers), and the "where" (chosen host country). Finally, companies were requested to cite problems (if any) they experienced when staying abroad. The third and final part of the questionnaire was focused on the back-/near-shoring decisions which have been investigated according to the same variables adopted for the offshoring phase. Finally, companies were asked to give an overall evaluation of the relocation of second degree they implemented.

As far as the Spanish companies are concerned, the questionnaire was addressed to footwear manufacturers across all the country (even though $60 \%$ of them are located in the Alicante industrial district). The average size of the responding firms is similar to that of the whole population ( $80 \%$ with fewer than 20 employees) and with a high presence in international markets (50\% of the firms export over $50 \%$ of their total sales). After receiving 103 completed questionnaires, attention was focused on the 33 that had implemented offshoring strategies. All of them completed a questionnaire specifically focused on the back- and near-shoring decisions and 15 out of the 33 companies declared they had also implemented back- and/or near-shoring strategies.

With respect to the Italian companies, a list of 17 companies that implemented relocation of second degree decisions (including further offshoring) was obtained from the Italian Association of Shoemakers. The list was derived from a previous survey among the 600 members of the Association which obtained a response rate higher than $30 \%$. After contacting each of the 17 companies, 10 of them declared to have implemented back- and/or near-shoring strategies (while the other seven implemented only further offshoring decisions). All companies were requested to complete the same questionnaire adopted for the Spanish companies.

Based on questionnaire completed by the 25 companies (15 Spanish and 10 Italian), a total number of 41 relocation of second degree decisions was found, of which 31 were back-shoring and 10 near-shoring. Therefore, each surveyed company implemented 1.6 decisions on average. This finding enlarges previous evidence by [10] in terms of backshoring strategies, showing that multiple relocation decisions also include the nearshoring phenomenon. In this respect, no differences were found between the two countries; however, the multiple relocation decisions implemented by Italian companies were generally hybrid, i.e., they simultaneously implemented both, the back- and nearshoring alternatives. Finally, multi-shoring strategies have mainly been implemented by medium-sized Italian firms (1.8 decisions for companies) while Spanish firms show no relevant differences between small- and medium-sized ones $(2.3$ decisions on average).The "offshoring time", i.e., the year when the company started to relocate their production activities abroad, emerges as another difference between Italian and Spanish firms. Except for two isolated cases in the '70s and ' 80 s (one for each country), Italian firms have generally off-shored during the '90s (8 out of 10) while Spanish ones only in the first decade of the 21 st century ( 7 out of 15 ), which is in accordance with the results presented by [52] on their analysis of the whole industry. Since Spain was generally considered one of the low labour cost countries in Western Europe (along with Portugal and Greece), the latter evidence might be explained with the opening of the World Trade 
Organization to China in 2002. This event increased the price pressure on European companies (especially those that had in their low labour costs a source of competitive advantage) and pushed them to off-shore [53].

Comparing the main features of two sub-samples (Table 1), Italian firms are larger; moreover, they implemented the two relocation strategies under analysis almost equivally ( 8 back- vs. 7 near-shoring evidence) while Spanish companies rarely nearshored (23 back- vs. 3 near-shoring evidence).

Table 1. Sample characterization by firm's size and relocation strategy

\begin{tabular}{|c|c|c|c|c|c|c|c|c|c|}
\hline \multirow{2}{*}{ Size } & \multicolumn{3}{|c|}{ Italy (N. of decisions) } & \multicolumn{3}{|c|}{ Spain (N. of decisions) } & \multicolumn{3}{|c|}{ Total (N. of decisions) } \\
\hline & Firms & Back & Near & Firms & Back & Near & Firms & Back & Near \\
\hline $\mathbf{L}$ & 4 & 1 & 5 & & & & 4 & 1 & 5 \\
\hline Me & 4 & 5 & 2 & 4 & 7 & 2 & 8 & 12 & 4 \\
\hline $\mathbf{S}$ & 2 & 2 & & 4 & 8 & 1 & 6 & 10 & 1 \\
\hline $\mathbf{M i}$ & & & & 7 & 8 & & 7 & 8 & \\
\hline Total & 10 & 8 & 7 & 15 & 23 & 3 & 25 & 31 & 10 \\
\hline
\end{tabular}

Note: L: Large, Me: Medium, S: Small, Mi: Micro

The empirical analysis, which aimed to verify the hypotheses proposed in section 1.3 , is based on data provided by the two surveys described earlier. The idea is to assess, by means of a statistical test, whether the percentage of smaller firms that back-shore is smaller than that of firms that nearshore (HP 1), or whether some of the reasons and barriers to re-shore are more important in the group of firms that back-shored than in the group that near-shored. Given there are two kinds of variables to test whether they are differently distributed in the group of back-shoring companies than in the group of nearshoring ones, two different tests will be used. For binary variables (such as being small or large) a chi-square test for the differences between the two groups of interests was adopted.

The variables that capture the elements of HP 2 (reshoring motivations) and of HP 3 (reshoring barriers) have been measured through an indicator that is registered on a Likert scale from 1 to 5 . For this reason, the hypotheses will be tested using a test of equality of means that does not impose equality of variances between the two groups. In the table of results, it will be indicated if the hypotheses that the two means are equal (i.e., the characteristic is equally important for back-shoring and near-shoring firms) are accepted or rejected at the standard significance level.

\section{Findings}

The results of the statistical analysis presented in Table 2 allow us to differentiate the group of firms that reshored to near countries (near-shores) from those that returned manufacturing activities to their home country (back-shorers). The characteristics have been grouped within three dimensions: i) firm's characteristics, ii) reshoring motivations, and iii) barriers to reshoring. 
Table 2 Comparison of back-shoring and near-shoring activities

\begin{tabular}{|c|c|c|c|c|}
\hline & Back-shorers & Near-shorers & Test & \\
\hline \multicolumn{5}{|l|}{ Firm characteristics } \\
\hline Size $(\%$ of $\mathrm{L} / \mathrm{M} / \mathrm{S})$ & $3.2 / 38.7 / 58.1$ & $50 / 40 / 10$ & 0.011 & $* *$ \\
\hline \multicolumn{5}{|l|}{ Motivations } \\
\hline "Made in" effect & 3.000 & 3.000 & - & \\
\hline Availability of skilled contractors & 4.348 & 2.833 & 2.362 & $*$ \\
\hline Government aid & 1.722 & 1.143 & 2.274 & $* *$ \\
\hline \multicolumn{5}{|l|}{ Barriers } \\
\hline Find new contractors/employees & 2.706 & 1.400 & 2.991 & $* *$ \\
\hline Creation new manuf. competences & 3.286 & 1.000 & 3.200 & $* *$ \\
\hline
\end{tabular}

Note: ${ }^{*}, * *$ Indicate acceptance of the hypothesis of different values between the two groups at $90 \%$ and $95 \%$ of confidence respectively

Concerning the firm, we observe that near-shorers are larger than back-shorers, confirming HP 1. As different scholars have pointed out (see, among others, [48] [49] [50]), the strategy of locating production activities in a foreign location requires a minimum size of the firm in order to be profitable. Therefore, it can be justified that the firms that back-shore are smaller than those that still have part of their production abroad. More specifically, this is consistent with the previous findings in the extant literature.

The motivations for back-shoring - instead of near-shoring - point to the availability of skilled contractors as well as government aid. Firms that back-shored indicate these were important reasons ( 4.4 points over 5 ), confirming HP $2 b$ and HP $2 c$. Unexpectedly, the "made in" effect driver has not emerged as statistically different between both subgroups (back-shorers vs. near-shorers); therefore HP 2a is not confirmed. This unexpected result - when compared with previous empirical analysis (see, for instance, [11] and [12]) could, at least partially, be explained by the EU law on the "made in" label, since it allows companies to use it also in the case of some low-value production phases (e.g. the production of uppers in the footwear industry).

As far as barriers encountered in relocating the manufacturing activities within the home country/region are concerned, back-shorers find more inconveniences than nearshorers regarding creating new competences and finding new contractors. Therefore, HP $3 \mathrm{a}$ and $\mathrm{HP} 3 \mathrm{~b}$ are confirmed.

\section{Concluding remarks}

The paper offers a first attempt to characterize variables that may influence decisions regarding where to relocate manufacturing activities previously offshored. More specifically, three sets of variables seem to influence the preference for back-shoring (relocation to the home country) instead of near-shoring (relocation to the home region): size, motivations and barriers. To the best of our knowledge, this is the first attempt to compare back- and near-shoring alternatives; therefore our findings may support further investigations within the academic debate on relocations of second degree [4]. At the same time, our findings offer some useful insights for both practitioners (at least those involved in the footwear industry) and policy makers. For both the categories, the 
availability of skilled human resources (either to be enrolled or available within the company contractors) emerges as the most critical issue. As previous studies have demonstrated, intensive offshoring processes can produce negative impacts on the "industrial commons" available domestically [54] [55], thus reducing favourable conditions for back-shoring and increasing the time for their implementation. In fact, the domestic resources the firm can leverage for its new home production could particularly influence the opportunity, intensity, and speed of relocations to the home country. In this respect, countries with a higher presence of manufacturing activities - such as Italy [56] - are in a better position to sustain the processes of relocation to the home countries of their firms than other countries. In cases where the country (i.e. UK) has lost most of its industrial structure over the years, the firm should invest in and spend time on reconfiguring and re-building such conditions [57]. This is an important domain in which policies have to invest, for instance, through intensive programmes to sustain vocational training and other interventions for maintaining and renovating domestic skills. In this respect, it is worth noting that the fashion group LVMH has recently decided to open a corporate school in Tuscany (Central Italy) to train future technicians for its leather business through collaboration with the Tuscany Regional Government.

However, the small size of the investigated sample and the focus on the footwear industry does not allow us to propose generalizations of our preliminary findings. Further researchers should replicate such an investigation addressing larger populations and several industries.

\section{References}

[1] K. Ferdows, Making the most of foreign factories, Harvard Business Review, vol. 75 n. 2, 1997, pp. 7388.

[2] F. A. Huq, I. N. Chowdhury and R. D. Klassen, Social management capabilities of multinational buying firms and their emerging market suppliers: An exploratory study of the clothing industry, Journal of Operations Management, vol. 46, 2016, pp. 19-37.

[3] K. Ferdows, Keeping up with growing complexity of managing global operations, International Journal of Operations and Production Management, vol. 38 n. 2, 2018, pp. 390-402.

[4] P. Barbieri, S. Elia, L. Fratocchi, and R. Golini, Relocation of second degree: Moving towards a new place or returning home?, Journal of Purchasing and Supply Management, 2019, doi:10.1016/j.pursup.2018.12.003.

[5] L. Fratocchi, C. Di Mauro, P. Barbieri, G. Nassimbeni, and A. Zanoni, When manufacturing moves back: Concepts and questions, Journal of Purchasing and Supply Management, vol. 20 n. 1, 2014, pp. 54-59.

[6] K. Foerstl, J. F. Kirchoff and L. Bals, Reshoring and insourcing: drivers and future research directions, International Journal of Physical Distribution \& Logistics Management, vol. 46 n. 5, 2016, pp. 492515 .

[7] J. Johanson and J.-E. Vahlne, The internationalization process of the firm: A model of knowledge development and increasing foreign market commitments, Journal of International Business Studies, vol. 8 n. 1, 1977, pp. 23-32.

[8] J. Johanson and J.-E. Vahlne, The mechanism of internationalization, International Marketing Review, vol. 7 n. 4, 1990, pp. 11-24.

[9] T. Vissak, Nonlinear internationalization: A neglected topic in international business research. In T. Devinney et al. (eds.): The past, present and future of international business \& management, pp. 559 580, Advances in International Management, 2010.

[10] L. Fratocchi, A. Ancarani, P. Barbieri, C. Di Mauro, G. Nassimbeni, M. Sartor, M. Vignoli, and A. Zanoni, Manufacturing back-reshoring as a nonlinear internationalization process, in Van Tulder, R. et al. (eds.): The Future of Global Organizing, Progress in International Business Research, pp. 367-405, 2015 . 
[11] L. Fratocchi, A. Ancarani, P. Barbieri, C. Di Mauro, G. Nassimbeni, M. Sartor, M. Vignoli and A. Zanoni, Motivations of manufacturing reshoring: an interpretative framework, International Journal of Physical Distribution \& Logistics Management, vol. 46 n. 2, 2016, pp. 98-127.

[12] P. Barbieri, F. Ciabuschi, L. Fratocchi, and M. Vignoli, What do we know about manufacturing reshoring?, Journal of Global Operations and Strategic Sourcing, vol. 11 n.1, 2018, pp. 79-122.

[13] J. Stentoft, J. Olhager, J. Heikkilä and L. Thoms, Manufacturing backshoring: a systematic literature review, Operations Management Research, vol. 9 n. 3, 2016, pp. 53-61.

[14] B. Wiesmann, J. R. Snoei, P. Hilletofth, and D. Eriksson, Drivers and barriers to reshoring: a literature review on offshoring in reverse, European Business Review, vol. 29 n. 1, 2017, pp. 15- 42.

[15] D. Slepniov, S. Brazinskas and B. V. Wæhrens, Nearshoring practices: An exploratory study of Scandinavian manufacturers and Lithuanian vendor firms, Baltic Journal of Management, vol. 8 n.1, 2013, pp.5-26.

[16] C. Di Mauro, L. Fratocchi, G. Orzes and M. Sartor, Offshoring and backshoring: A multiple case study analysis, Journal of Purchasing and Supply Management, vol. 24 n. 2, 2018, pp. 108-134.

[17] U. Yu and J., Kim, Financial productivity issues of offshore and "Made-in-USA" through reshoring, Journal of Fashion Marketing and Management, vol. 22 n. 3, 2018, pp. 317-334.

[18] B. Piatanesi and J. M. Arauzo-Carod, Backshoring and nearshoring: An overview, Growth and Change, vol. 50 n. 3, 2019, pp. 806-823.

[19] L. Bals, J. F. Kirchoff and K. Foerstl, Exploring the reshoring and insourcing decision making process: toward an agenda for future research, Operations Management Research, vol. 9 n. 3-4, 2016, pp. 102 116.

[20] A. Rashid and L. Barnes, Country of origin: reshoring implication in the context of the UK fashion industry. In A. Vecchi, (ed.): Reshoring of manufacturing: drivers, opportunities, and challenges. Measuring operations performance, pp. 183-201, 2017.

[21] C. Martínez-Mora and F. Merino, Offshoring in the Spanish footwear industry: A return journey?, Journal of Purchasing and Supply Management, vol. 20 n. 4, 2014, pp. 225-237.

[22] E. Baraldi, F. Ciabuschi, O. Lindahl and L. Fratocchi, A network perspective on the reshoring process: The relevance of the home- and the host-country contexts, Industrial Marketing Management, vol. 70, 2018, pp. 156-166.

[23] L. Fratocchi and S.C.L.D., Costa e Silva, Manufacturing back-shoring and direct brand creation in the footwear industry, Advances in Transdisciplinary Engineering, vol. 8, pp. 461-466.

[24] G. Kvedaravičiene, Development of nearshoring in global outsourcing market, Economics \& Management, 2008, pp. 125-126.

[25] G. S. Shamis, M. C. Green, S. M. Sorensen, and D. L. Kyle, Outsourcing, offshoring, nearshoring: what to do?, Journal of Accountancy, vol. 199 n. 6, 2005, p. 57.

[26] D. J. Kamann and V. Van Nieulande, A four-filter method for outsourcing to low-cost countries, Journal of Supply Chain Management, vol. 46 n. 2, 2010, pp. 64-79.

[27] T. Hutzschenreuter, J. C. Voll, and A. Verbeke, The impact of added cultural distance and cultural diversity on international expansion patterns: A Penrosean perspective, Journal of Management Studies, vol. 48 n. 2, 2011, pp. 305-329.

[28] M. Bettiol, M. Chiarvesio, E. Di Maria, C. Di Stefano and L. Fratocchi, What Happens After Offshoring? A Comprehensive Framework. In R. Tulder et al. (eds): International Business in a VUCA World: The Changing Role of States and Firms (Progress in International Business Research), vol. 14, pp. 227-249, 2019.

[29] A. Ancarani, C. Di Mauro, L. Fratocchi, G. Orzes and M. Sartor, Prior to reshoring: A duration analysis of foreign manufacturing ventures, International Journal of Production Economics, vol. 169, 2015, pp. $141-155$

[30] A. Zhang and G. Q. Huang, Impacts of business environment changes on global manufacturing outsourcing in China, Supply Chain Management: An International Journal, vol. 17 n. 2, 2012, pp. 138151 .

[31] A. V. Benstead, M. Stevenson and L. C. Hendry, Why and how do firms reshore? A contingency-based conceptual framework, Operations Management Research, vol. 10 n. 3-4, 2017, pp. 85-103.

[32] A. Boffelli, R. Golini, G. Orzes and S. Dotti, Reshoring decision-making and implementation processes: A multiple-case study. In 25th EurOMA Conference, 2018, p. 76.

[33] J. V. Gray, G. Esenduran, M. J. Rungtusanatham, K. Skowronski, Why in the world did they reshore? Examining small to medium-sized manufacturer decisions, Journal of Operation Management, vol. 4951, 2017, pp. 37-51.

[34] S. Kinkel, Future and impact of backshoring-Some conclusions from 15 years of research on German practices, Journal of Purchasing and Supply Management, vol. 20 n.1, 2014, pp. 63-65.

[35] S. Kinkel and S. Maloca, Drivers and antecedents of manufacturing offshoring and backshoring-A German perspective, Journal of Purchasing and Supply Management, vol. 15 n. 3, 2009, pp. 154-165. 
[36] B. Dachs, S. Kinkel, A. Jäger and I. Palčič, Backshoring of production activities in European manufacturing, Journal of Purchasing and Supply Management, vol. 25 n. 3, 2019, 100531.

[37] J. Heikkilä, M. Martinsuo and S. Nenonen, Backshoring of production in the context of a small and open Nordic economy, Journal of Manufacturing Technology Management, vol. 29 n. 4, 2018, pp. 658-675.

[38] J. Heikkilä, S. Nenonen, J. Olhager and J. Stentoft, Manufacturing relocation abroad and back: empirical evidence from the Nordic countries, World Review of Intermodal Transportation Research, vol. 7 n. 3 , 2018, pp. 221-240.

[39] M. Johansson and J. Olhager, Comparing offshoring and backshoring: The role of manufacturing site location factors and their impact on post-relocation performance, International Journal of Production Economics, 205, 2018, pp. 37-46.

[40] S. Canham, and R. T. Hamilton, SME internationalisation: offshoring, "backshoring", or staying at home in New Zealand, Strategic Outsourcing: An International Journal, vol. 6 n. 3, 2013, pp. 277-291.

[41] F. Fel and E. Griette, Near-reshoring your supplies from China: a good deal for financial motives too, Strategic Direction, vol. 33 n. 2, 2017, pp. 24-16.

[42] W. Johnson, Is nearshoring right for your product?: As China matures, a host of factors could rebalance the geographical supply chain, Printed Circuit Design \& Fab, 2012.

[43] L. Chen and B. Hu, Is reshoring better than offshoring? The effect of offshore supply dependence, Manufacturing \& Service Operations Management, vol. 19 n. 2, 2017, pp. 166-184.

[44] B. B. Nujen, L. Lillebrygfjeld, R. HalseDamm, H. Gammelsæter, Managing reversed (global) outsourcing-the role of knowledge, technology and time, Journal of Manufacturing Technology Management, vol. 29 n. 4, 2018, pp. 676-698.

[45] L. Halse, B. Nujen and H. Solli-Sæther, The Role of Institutional Context in Backshoring Decisions. In Tulder, R. et al. (eds.): International Business in a VUCA World: The Changing Role of States and Firms (Progress in International Business Research), vol. 14, pp. 251-268, 2019.

[46] G. Engström , P. Hilletofth, D. Eriksson and K. Sollander, Drivers and barriers of reshoring in the Swedish manufacturing industry, World Review of Intermodal Transportation Research, vol. 7 n. 3 , 2018, pp. 195-220.

[47] G. Engström, K. Sollander, P. Hilletofth, and D. Eriksson, Reshoring drivers and barriers in the Swedish manufacturing industry, Journal of Global Operation and Strategic Sourcing, vol. 11 n. 2, 2018, pp. 174-201.

[48] V. Anderson, S. Graham and P. Lawrence, Learning to internationalize, Journal of Management Development, vol. 17 n. 7, 1998, pp. 492-502.

[49] I. Fillis, Small firm internationalisation: an investigative survey and future research directions, Management Decision, vol. 39 n. 9, 2001, pp. 767-783.

[50] J. Johanson and J-E. Vahlne, The internationalization process of a firm: a model of knowledge development and increasing foreign market commitments, Journal of International Business Studies, vol. 8, 1977, pp. 23-32.

[51] S. Grappi, S. Romani and R. P. Bagozzi, Consumer stakeholder responses to reshoring strategies, Journal of the Academy of Marketing Science, vol. 43 n. 4, 2015, pp. 453-471.

[52] G. L. Fontana and J. A. Miranda, Design and fashion as determinants of industrial competitiveness: a comparative study of the evolution of the footwear industry in Italy and Spain. In G. Motta and A. Biagini (Eds), Fashion through History: Costumes, Symbols, Communication, vol. 2, pp. 49-58, 2017.

[53] A. J. Verdu, J. M. Gómez-Gras and J. Martínez-Mateo, Value creation through production offshoreinshore strategies in a footwear industry cluster: A coevolutionary perspective, International Business Review, vol. 21 n. 3, 2012, pp. 342-356.

[54] G. P. Pisano and W. C. Shih, Does America Really Need Manufacturing, Harvard Business Review, vol. 90 n. 3, 2012, pp. 94-102.

[55] G. P. Pisano and W. C. Shih, (2012b), Producing Prosperity. Why America Needs a Manufacturing Renaissance, Harvard Business Review Press, 2012, Boston, MA.

[56] V. De Marchi, E. De Maria and G. Gereffi, (eds.), Local Clusters in Global Value Chains, London: Routledge, 2018.

[57] D. Bailey and L. De Propris, Reshoring: opportunities and limits for manufacturing in the UK - the case of the auto sector, Revue D'économie Industrielle, vol. 1 n. 145, 2014, pp. 45-61. 